Subscriber access provided by King Abdullah University of Science and Technology Library

Article

\title{
Carrier Transport Enhancement in Conjugated Polymers through Interfacial Self-Assembly of Solution-State Aggregates
}

Kui Zhao, Hadayat Ullah Khan, Ruipeng Li, Hanlin Hu, and Aram Amassian

ACS Appl. Mater. Interfaces, Just Accepted Manuscript • DOI: 10.1021/acsami.6b04508 • Publication Date (Web): 13 Jul 2016

Downloaded from http://pubs.acs.org on July 19, 2016

\section{Just Accepted}

"Just Accepted" manuscripts have been peer-reviewed and accepted for publication. They are posted online prior to technical editing, formatting for publication and author proofing. The American Chemical Society provides "Just Accepted" as a free service to the research community to expedite the dissemination of scientific material as soon as possible after acceptance. "Just Accepted" manuscripts appear in full in PDF format accompanied by an HTML abstract. "Just Accepted" manuscripts have been fully peer reviewed, but should not be considered the official version of record. They are accessible to all readers and citable by the Digital Object Identifier (DOI®). "Just Accepted" is an optional service offered to authors. Therefore, the "Just Accepted" Web site may not include all articles that will be published in the journal. After a manuscript is technically edited and formatted, it will be removed from the "Just Accepted" Web site and published as an ASAP article. Note that technical editing may introduce minor changes to the manuscript text and/or graphics which could affect content, and all legal disclaimers and ethical guidelines that apply to the journal pertain. ACS cannot be held responsible for errors or consequences arising from the use of information contained in these "Just Accepted" manuscripts. 


\begin{abstract}
:
We demonstrate that local and long range orders of poly(3-hexylthiophene) (P3HT) semicrystalline films can be synergistically improved by combining chemical functionalization of the substrate with solution-state disentanglement and pre-aggregation of P3HT in a theta solvent, leading to a very significant enhancement of the field effect carrier mobility. The pre-aggregation and surface functionalization effects combine to enhance the carrier mobility nearly 100 -fold as compared with standard film preparation by spin-coating, and nearly 10 -fold increase over the benefits of pre-aggregation alone. In situ quartz crystal microbalance with dissipation (QCM-D) experiments reveal enhanced deposition of pre-aggregates on surfaces modified with an alkyl-terminated self-assembled monolayer (SAM) in comparison to un-aggregated polymer chains. Additional investigations reveal the combined pre-aggregation and surface functionalization significantly enhances local order of the conjugated polymer through planarization and extension of the conjugated backbone of the polymer which clearly translate to significant improvements of
\end{abstract}


carrier transport at the semiconductor-dielectric interface in organic thin film transistors. This study points to opportunities in combining complementary routes, such as well-known pre-aggregation with substrate chemical functionalization, to enhance the polymer self-assembly and improve its interfacial order with benefits for transport properties.

Keywords: conjugated polymers; charge transport; organic thin film transistor; aggregation; surface functionalization

\section{INTRODUCTION}

Conjugated polymers have attracted a great deal of attention in recent years because of their ever-improving electronic, optoelectronic and photovoltaic properties. $^{1-4}$ The semi-flexible poly(3-hexylthiophene) (P3HT) is the archetypal semi-crystalline conjugated polymer used in organic electronics and photovoltaics and has been investigated extensively to develop an understanding of structure-property-performance relations. ${ }^{5-10}$ A number of recent studies have demonstrated that molecular ordering along the polymer backbone and between chains is far more important to carrier transport in high molecular weight (Mw) polymer films than domain boundaries. ${ }^{11-16}$ However, high Mw semi-flexible polymers are thought to be difficult to push into a highly molecularly ordered state due to entanglements and interactions which can inhibit molecular diffusion and challenge conformational transitions. ${ }^{11,13,17}$ Polymer crystallization improves the molecular stacking order and planarization of the backbone in the solid state, hence there have been a number of reports linking crystalline order to carrier transport. ${ }^{7,18,19}$ Along this line, several strategies have been pursued to control molecular self-assembly and thin film microstructure, including by decreasing chain entanglements in the solution state, ${ }^{12,13,17}$ tuning solution-processing conditions, ${ }^{20-24}$ surface functionalization with a self-assembled monolayer (SAM) ${ }^{25-27}$ and applying post-deposition thermal/solvent vapour annealing. ${ }^{28-30}$ 
It has been shown that chain entanglements in high Mw polymers mediate pre-aggregation in theta solvents prior to solution-casting. ${ }^{12,13}$ Chain entanglements inhibit chain conformational changes in conditions where the solution approaches its solubility limit. Hence, disentanglement results in facile pre-aggregation of a large number of nuclei with uniform size distribution, leading - among other things - to a reduction of the specific viscosity of the solution and to easier diffusivity of pre-aggregates and chains. ${ }^{12,31}$ During solution drying, disentangled chains and pre-aggregates therefore more easily assemble into structures exhibiting enhanced backbone planarity, lamellar thickness and extended $\pi-\pi^{*}$ conjugation. $^{32}$

Molecular self-assembly during solution-casting can be influenced by surface functionalization with a SAM, an effect widely recognized in solution-processed small-molecule organic semiconductors. ${ }^{33-36}$ In case of polymers, the effects have been attributed to minimizing polar moieties $^{37,38}$ and inducing molecular orientation and interfacial order at the dielectric surface. ${ }^{39-42}$ We therefore take the view that the enhanced mobility of species in a disentangled polymer solution can be synergistically coupled with appropriate chemical modifications of the substrate to enhance self-assembly and formation of high quality semicrystalline conjugated polymers.

In this study, we demonstrate the powerful benefits of combining polymer aggregation in a theta solution with chain disentanglement and surface chemical functionalization at the solution-solid interface to induce important and meaningful changes in the local order and backbone planarization of a semiflexible conjugated polymer. The combined effects yield significant impact on carrier transport in the conjugated polymer film in the context of organic thin film transistors (OTFTs). In situ quartz crystal microbalance with dissipation (QCM-D) experiments reveal important differences in the rate and mechanism of self-assembly of the polymer for pristine and well-aggregated formulations on untreated and chemically modified surfaces. The resulting films were subsequently characterized in terms of microstructure and morphology using a combination of x-ray diffraction, grazing incidence wide angle X-ray scattering (GIWAXS), and transmission electron microscopy 
(TEM). Ultraviolet-visible (UV-Vis) absorption spectroscopy was combined with quantitative analysis using the Spano model fit approach to estimate the photophysical aggregation and backbone planarity. ${ }^{43,44}$ Our investigation clearly demonstrates that aggregating high quality polymer domains in a theta solvent and letting the solution dry on an alkyl-terminated SAM influences its deposition behaviour to the point that local and long range orders are affected and the carrier mobility of the polymer semiconductor is greatly affected. These results point to existence of synergistic routes to enhancing the transport properties of conjugated polymers in the context of OTFT applications and beyond.

\section{EXPERIMENTAL METHODOLOGY}

Materials: Regioregular P3HT $(\mathrm{Mw}=67 \mathrm{kDa}$; regioregularity RR = 98.5\%; Sigma-Aldrich Co. $)$ and toluene $(99.8 \%$ anhydrous; Sigma-Aldrich Co.) were used without further purification.

Pre-treatment: P3HT was dissolved in $1 \mathrm{~mL}$ of toluene $(0.5 \mathrm{wt} . \%)$ at elevated temperature $60{ }^{\circ} \mathrm{C}$ for 10 min and then kept stirring in dark environment over two days at room temperature. A small glass vial of the P3HT solution was placed in an ultrasonic bath at room temperature for $0,2,4,6$ and 8 min at a power level of $(30 \mathrm{~W} / \mathrm{L})$ to alter the solution state aggregation.

Surface-treatment: $46 \mu \mathrm{l} / \mathrm{mL}$ octyltrichlorosilane (OTS) solution in toluene was cast onto a UV/ozone cleaned $\mathrm{Si} / \mathrm{SiO}_{2}$ wafer to cover the entire surface and was allowed to partially assemble for $30 \mathrm{~min}$; the substrate was then washed with toluene and rinsed with DI water. For TEM characterization, $30 \mathrm{~nm}$ PEDOT-PSS layer was cast on $\mathrm{Si} / \mathrm{SiO}_{2}$ wafer and dried at $110{ }^{\circ} \mathrm{C}$ for 10 min, followed by planting OTS monolayer.

Post-treatment: Annealing has been carried out at temperatures from $130{ }^{\circ} \mathrm{C}$ for $5 \mathrm{~min}$ in $\mathrm{N}_{2}$ - filled glove-box, followed by a slow cooling down to room temperature.

Device Fabrication and Characterization: As ultrasonicated for various time period $0.5 \mathrm{wt} \%$ solutions of organic semiconductor P3HT in toluene were spin-coated (SPIN 150) onto OTS treated 
substrates at a rate of $1000 \mathrm{rpm}$ for $30 \mathrm{sec}$. Gold source -drain electrodes were evaporated through a shadow mask with a channel width $(W)$ of $500 \mu \mathrm{m}$ and length $(L)$ of $30 \mu \mathrm{m}$. All electrical measurements were performed with a Keithely 4200 Semiconductor Characterization System in ambient air.

Characterizations: The thickness of spin-coated films was measured by M-2000 variable angle spectroscopic ellipsometer (J. A. Woollam. Inc). The different incidence angle $55^{\circ}, 65^{\circ}$ and $75^{\circ}$ were mounted for accurate fitting. Its spectra spanned over ca. $200 \mathrm{~nm}$ wavelengths to ca. $1800 \mathrm{~nm}$. The thin-films showed ca. $30 \mathrm{~nm}$. Analysis of the ellipsometric data was performed using complete EASE $^{\mathrm{TM}}$ and WVASE32 software (J.A. Woollam Co., Inc.).

Rheology measurements were carried out on an Anton Paar MCR-301 rheometer at a constant shear rate of $\left(100 \mathrm{~s}^{-1}\right)$.

Quartz Crystal Microbalance and Dissipation (QCM-D): QCM-D measurements were obtained in Flow Module accessory of the E4 instrument with a flow speed of $50 \mu \mathrm{L} / \mathrm{min}$ at room temperature (Q-sense). A QCM-D (Q-sense) and Quartz sensor crystals (Q-sense) coated with/without OTS were used to characterize the effect of the substrate modification on the P3HT precursors adsorption behaviour. The results were interpreted with a Kelvin-Voigt viscoelastic model to obtain the deposited thickness. The thickness of the seed layer, with the density of polymer $1.3 \mathrm{~g} / \mathrm{mm}^{3}$, was calculated by Voigt model from the $3^{\text {rd }}, 5^{\text {th }}, 7^{\text {th }}$ and $9^{\text {th }}$ overtones of frequency and dissipation. Changes in dissipation and frequency of the fifth overtone are represented in the main text.

Transmission electron microscopy (TEM): TEM experiments were carried out on a FEI Tecnai 12 operated at $120 \mathrm{kV}$ accelerating voltage. Samples for TEM were prepared by floating thin-film on a 300 mesh copper grid. The surface analysis for the samples was carried out by AFM "Agilent 5400 SPM".

Grazing incidence wide angle X-ray scattering (GIWAXS): GIWAXS measurement was carried out on D-line, Cornell High Energy Synchrotron Source (CHESS) at Cornell University. A 0.5 x 0.1 
$\mathrm{mm}$ beam size with a wavelength of $1.1688 \AA$ and wide band pass (1.47\%) was generated from double-bounce multilayer monochromator. The incidence angle was $0.15^{\circ}$ with respect to the substrate plane, as established by performing x-ray reflectivity using an ion chamber. A 50 x $50 \mathrm{~mm}$ charged coupling device (CCD) area detector (Medoptics) with pixel size of $46.9 \mu \mathrm{m}$ was placed at a distance of $101.21 \mathrm{~mm}$ from the sample stage. A $1.5 \mathrm{~mm}$-wide tantalum rod was used to block the intense scattering at low angles of incidence.

Grazing incidence X-ray diffraction (XRD): XRD measurement was carried out in a scanning interval of $2 \theta$ between 3 and 20. We employed an incident angle $(R=0.2)$ slightly above the critical angle $(\mathrm{Rc}=0.18)$.

\section{RESULTS AND DISCUSSION}

\subsection{Polymer entanglement and pre-aggregation in solution}

High Mw P3HT dissolved in a theta solvent, such as toluene at room temperature, is known to aggregate. ${ }^{17,45}$ However, chain entanglements due to the length of the polymer chains inhibit molecular diffusivity and coil-to-rod phase transformation, leading to poor nucleation/micro-crystallization in solution. Low energy ultrasonication has been shown to reduce chain entanglements and promote the formation of ordered aggregates in theta solvents, which can be confirmed by measuring the optical properties of the polymer solution. ${ }^{12,13}$ The UV-Vis absorption spectra of P3HT in toluene at room temperature (Figure 1a) show a clear absorption peak at ca. 605 $\mathrm{nm}$, associated to inter-chain interactions. ${ }^{46}$ Ultrasonication induces a significant increase in photophysical aggregation and effectively results in an increased local order in terms of intermolecular and intramolecular interactions. We also observe a slight decrease of the specific viscosity of the solution from 0.52 to 0.40 after treating the solution (Figure 1b), confirming a reduction of the chain entanglements in solution. These results, combined with prior analysis by dynamic light scattering, ${ }^{13,47}$ paint the pictures of the pristine and disentangled solutions illustrated in 
Figures 1c, whereby the ultrasonicated polymer solution is more akin to a suspension of monodisperse P3HT aggregates with few dissolved chains effectively reducing the number of entanglements in solution.

(a)

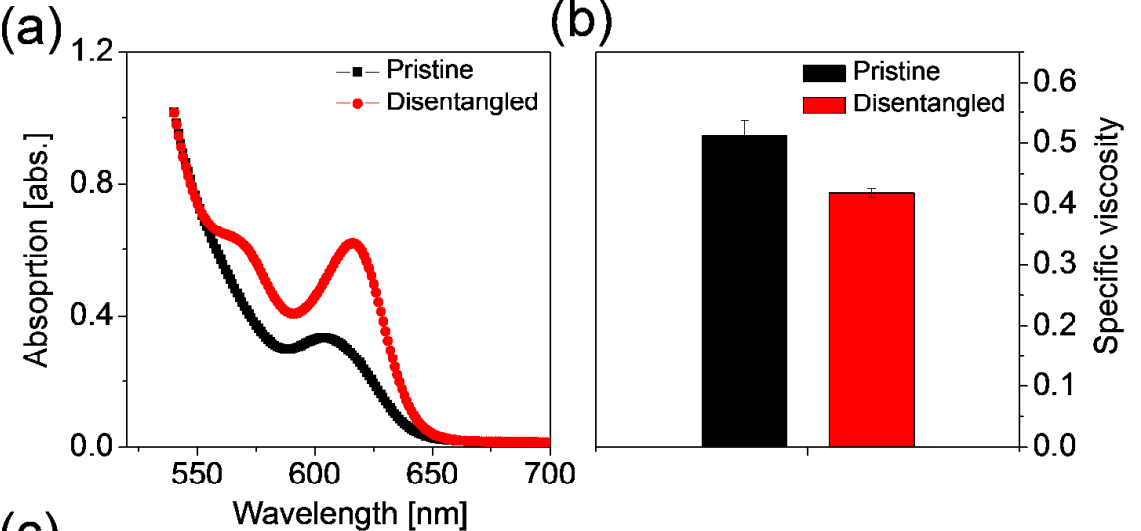

(c)

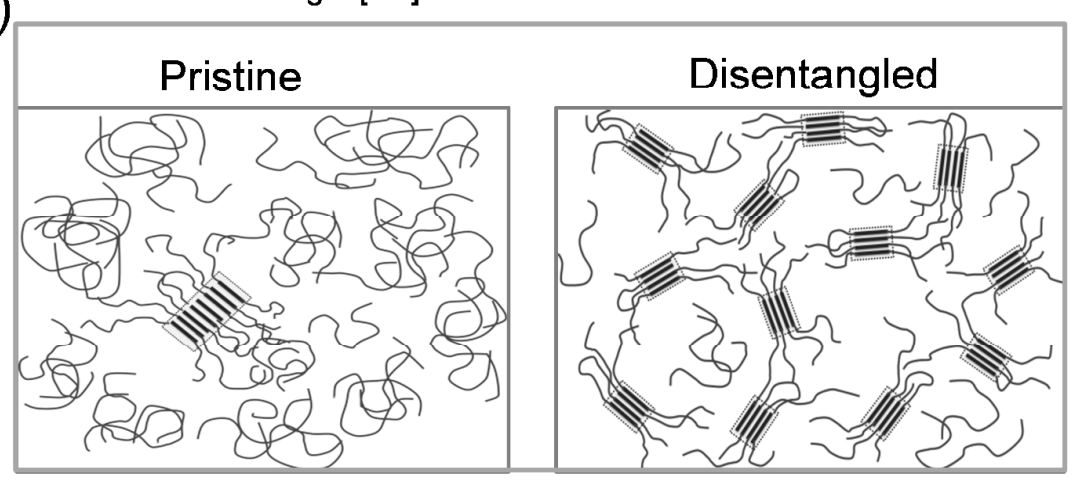

Figure 1. (a) Normalized UV-Vis absorption of P3HT solution showing chain disentanglements influencing pre-aggregation. (b) Specific viscosity of P3HT solution confirming low chain entanglements after solution treatment. (c) Schematic model showing solution state of polymer before and after chain disentanglements.

\subsection{OTFT device performance}

Organic thin film transistors in the bottom-gate top-contact (BGTC) architecture were fabricated on n-doped $\mathrm{Si}$ substrates (gate) with $\mathrm{SiO}_{2}$ as gate dielectric and evaporated gold source and drain (Figure 2a). The P3HT layer was spin-cast from a 0.5 wt.\% toluene solution treated with ultrasonication. ${ }^{13}$ In Figure $\mathbf{2 b}$, we plot the saturation hole mobility with respect to ultrasonication 
time for the as-cast (square) and thermal annealed (dot) films on untreated $\mathrm{SiO}_{2}$ gate dielectric (See Table S1 for details). The data reveal a $\sim 20$-fold increase of mobility between the as-cast $(0 \mathrm{~min})$ and ultrasonicated ( $6 \& 8 \mathrm{~min}$ ) cases. Thermal annealing further increases the carrier mobility of samples treated for 6 min or less, with the peak mobility observed at an optimal ultrasonication time of $4 \mathrm{~min}$ with a mobility of $0.015 \mathrm{~cm}^{2} \mathrm{~V}^{-1} \mathrm{~s}^{-1}$. It is important to note that the combination of ultrasonication and thermal annealing yields faster carrier transport than what can be achieved by annealing alone. Surface modification of the gate dielectric with an octadecyltrichlorosilane (OTS) SAM followed by annealing further improves carrier transport by nearly an order of magnitude. In the case of pristine solution the mobility increases to $0.035 \mathrm{~cm}^{2} \mathrm{~V}^{-1} \mathrm{~s}^{-1}$ on $\mathrm{OTS} / \mathrm{SiO}_{2}$, while ultrasonicated solutions yield a remarkable mobility as high as $0.156 \mathrm{~cm}^{2} \mathrm{~V}^{-1} \mathrm{~s}^{-1}$. This performance is two orders of magnitude superior to $\mathrm{P} 3 \mathrm{HT}$ films prepared from pristine solutions on untreated $\mathrm{SiO}_{2}$ without thermal annealing. Note that the impact of thermal annealing is more negligible when comparing surface modification and ultrasonication, which indicates potentially significantly hints that self-assembly behaviour of pre-aggregates on surface functionalized substrate influences P3HT order and charge mobility. The decreases in $V_{\text {th }}$ and increases in on/off ratio are summarized in Table S1 and Figure S1. As mobility increases, on/off ratio also increases while $V_{t h}$ decreases.

Surface functionalization-induced interfacial order was previously investigated by Salleo et al. through an ex situ study of thickness-dependent crystallinity and suggested the formation of a three-layer model. ${ }^{11}$ Importantly it has been suggested that surface functionalization has an enhancing effect on interfacial order, with the effect limited to within approximately $10 \mathrm{~nm}$ of the modified interface, ${ }^{11,40}$ which means that the increased molecular order of polymer film at the interface with the OTS-treated substrate may arise from the increased interfacial order in very thin (less than ca. $10 \mathrm{~nm}$ ) P3HT layer. Such benefits may arise from the interactions of the alkyl chains in the polymer with those of OTS, ${ }^{40}$ and this calls for deeper investigation through in situ methods to reveal whether polymer adsorption is responsible for this. 

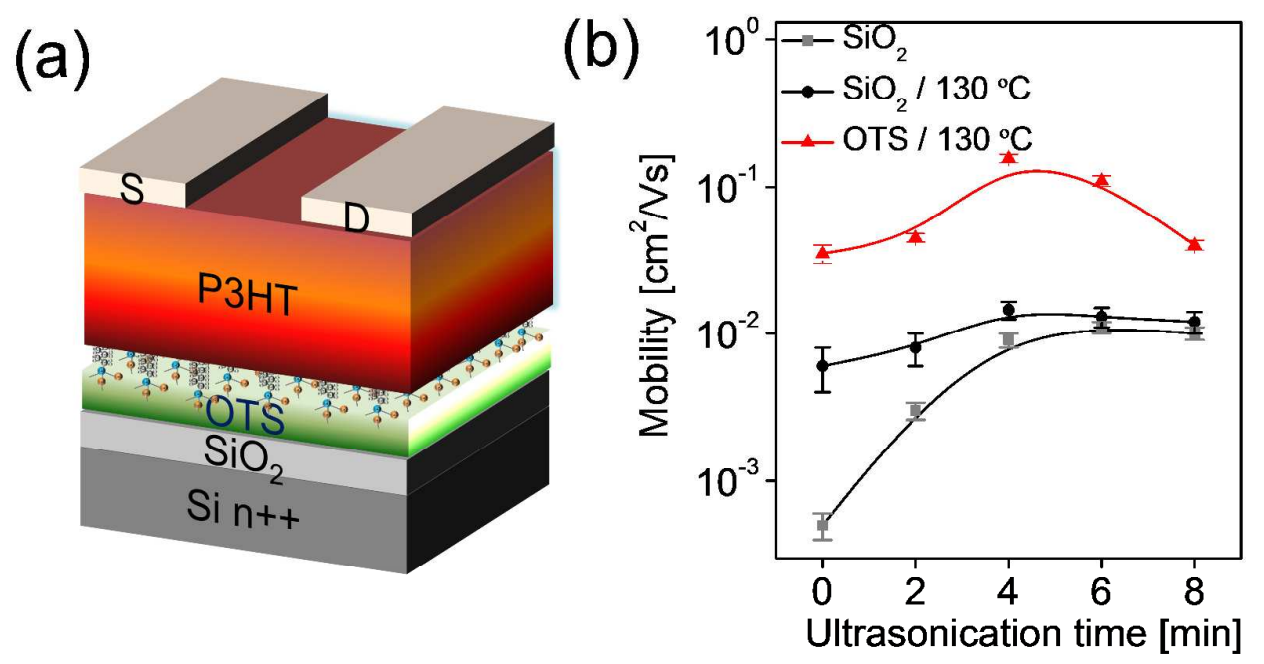

Figure 2. (a) Schematic representation of P3HT transistors in the bottom-gate top-contact (BGTC) architecture. (b) Saturation hole mobilities with respect to ultrasonication time for the as-cast and thermal annealed films on untreated $\mathrm{SiO}_{2}$ gate dielectric and OTS-treated $\mathrm{SiO}_{2}$. The average mobility and error bar are calculated from a minimum of 4 devices.

\subsection{P3HT thin film formation}

The disentanglement and pre-aggregation of P3HT via ultrasonication and the functionalization of surface with OTS SAM are expected to influence how the polymer film forms at the solid-liquid interface. ${ }^{11,13}$ This can be challenging to investigate, as optical and X-ray scattering techniques previously developed to investigate film formation probe mainly the bulk and surface of the drying film, rather than its buried interface. ${ }^{48-55}$ We have recently shown that thin film deposition at the solid-liquid interface, solvent vapour annealing and ligand exchange in colloidal quantum dot solids can be monitored using a quartz crystal microbalance with dissipation (QCM-D) capability. ${ }^{56-58}$ QCM-D measures the change of frequency $(\Delta f)$ and dissipation $(\Delta D)$ at the surface of the microbalance in relation to mass deposition or loss and changes in the viscoelastic properties of the 
adsorbed mass, respectively. ${ }^{59-61}$ For the purpose of our study, we evaluate the rate and extent of P3HT deposition at the solid-solution interface on untreated and OTS-treated $\mathrm{SiO}_{2}$-coated quartz sensor using pristine and ultrasonicated $(4 \mathrm{~min})$ solutions. The quartz crystal is stationary (not spinning) and the solution is cast in a closed flow cell so as to eliminate the effects of solution outflow and solvent evaporation. The P3HT solution (0.5 wt.\%) in toluene is continuously flown over the $\mathrm{SiO}_{2}$ or $\mathrm{SiO}_{2}$ /OTS-coated sensor, as shown in Figure 3a. 
(a)

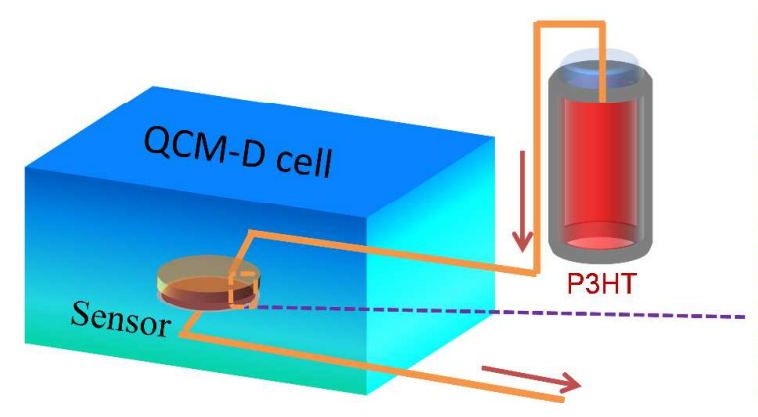

(b)

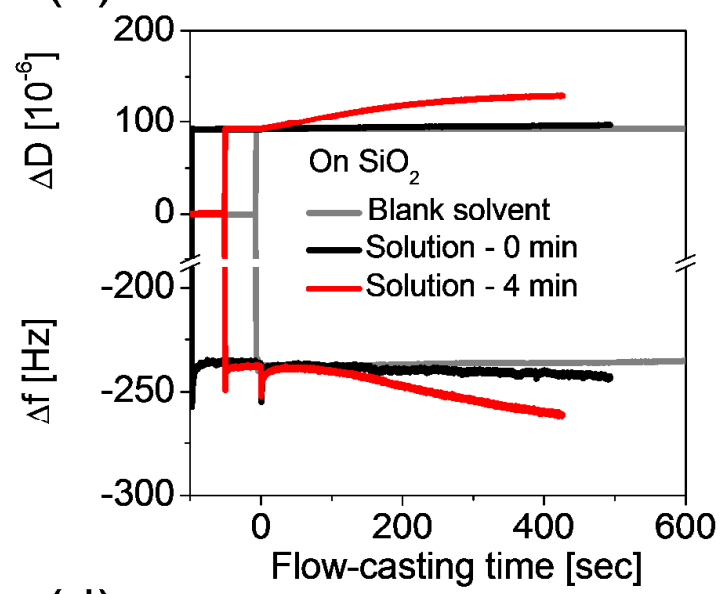

(d)

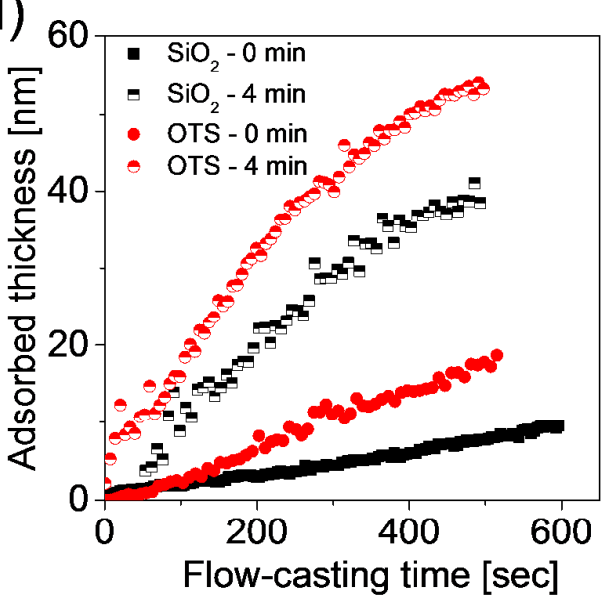

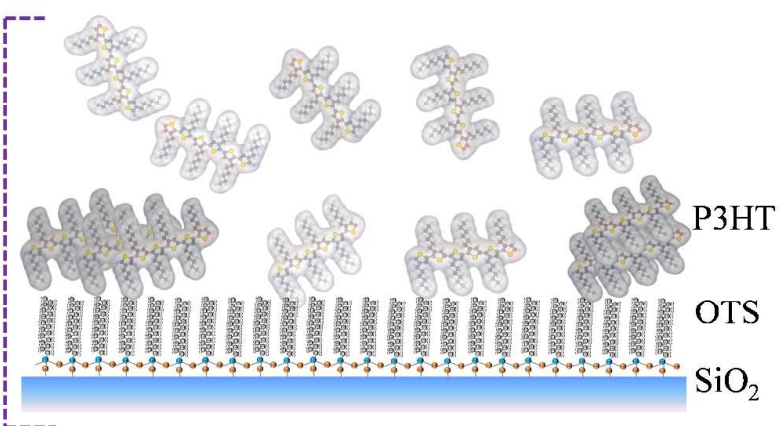

(c)

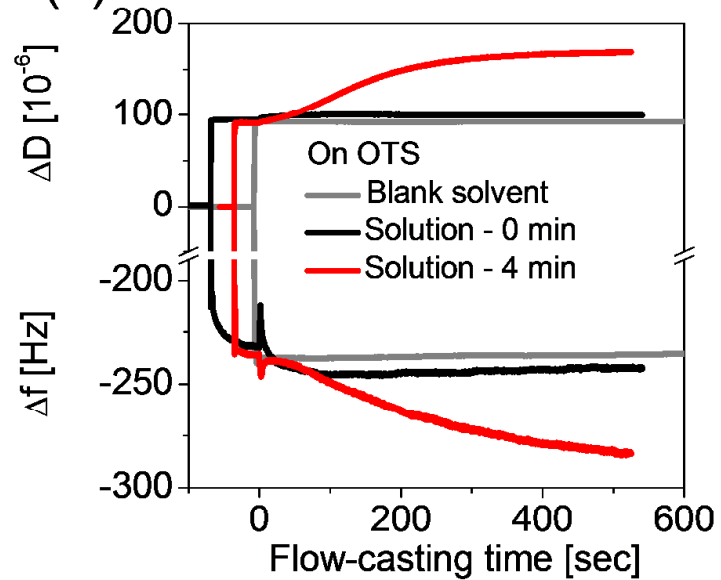

(e)

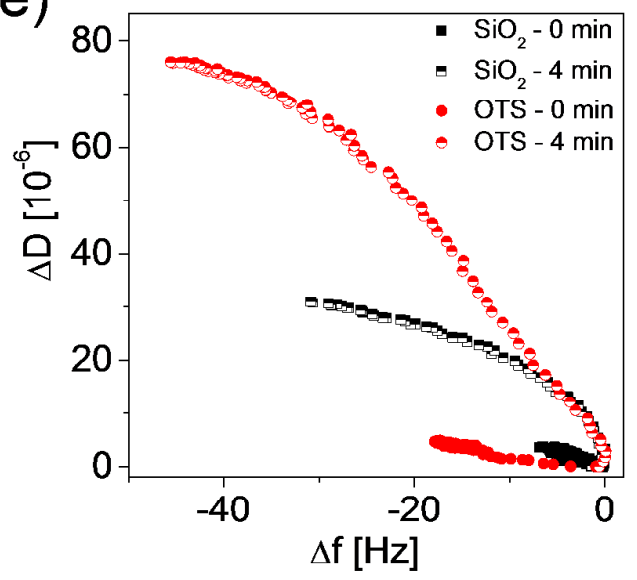

Figure 3. (a) Schematic illustration of the QCM-D closed flow cell containing a $\mathrm{SiO}_{2}$-coated quartz sensor. The P3HT solution is flown through the enclosed cell, preventing solvent evaporation. (b, c) Changes of frequency $(\Delta f)$ and dissipation $(\Delta D)$, respectively, for the blank solvent as well as the pristine and ultrasonicated solutions as they flow over the untreated and OTS-treated $\mathrm{SiO}_{2}$-coated quartz sensor. (d) The time-evolution of adsorbed thickness from pristine and ultrasonicated 
solutions on $\mathrm{SiO}_{2}$ and $\mathrm{SiO}_{2} / \mathrm{OTS}$ surfaces, as calculated using the Voigt model. (e) $\Delta D$ vs. $\Delta f$ trajectory plots for pristine and ultrasonicated solutions on untreated and OTS-treated $\mathrm{SiO}_{2}$-coated quartz sensor showing significant differences in slope and growth mechanism.

In Figures 3b and 3c, we plot the evolutions of $\Delta f$ and $\Delta D$ for the blank solvent, as well as for the pristine and ultrasonicated solutions as they flow over the $\mathrm{SiO}_{2}$ or $\mathrm{SiO}_{2} /$ OTS-coated sensor, respectively. The time-evolution of thickness (Figure 3d) of pristine and ultrasonicated solutions on $\mathrm{SiO}_{2}$ and $\mathrm{SiO}_{2} / \mathrm{OTS}$ surfaces was calculated using the Voigt model for viscoelastic materials, ${ }^{61,62}$ as detailed in supporting information and Figure S2. No mass uptake is detected when flowing the blank solvent. However, P3HT spontaneously deposits on the surface of the substrate, with a $\sim 10 \mathrm{~nm}$ P3HT film forming at a rate of $1 \mathrm{~nm} / \mathrm{min}$ on $\mathrm{SiO}_{2}$ from an untreated solution, increasing nearly five-fold to $4.8 \mathrm{~nm} / \mathrm{min}$ when an ultrasonicated solution is used on untreated substrate. The OTS-treatment further enhances the deposition rate to $>7 \mathrm{~nm} / \mathrm{min}$, indicating that P3HT aggregates assemble easily at the interface and perhaps promote further deposition of P3HT from the solution on the pre-aggregates assembled at the solid-solution interface. A closer look at the evolutions of $\Delta D$ vs. $\Delta f$ trajectory plots (Figure 3e) should reveal whether the P3HT deposition proceeds via the same mechanism or instead is influenced by pre-aggregation and/or functionalization of the substrate. In case of pristine $\mathrm{P} 3 \mathrm{HT}$ solutions, mass uptake (decrease of $\Delta f$ ) on either surface is accompanied with a modest increase of dissipation, indicating formation of a relatively compact layer. By contrast, when the solution is pre-aggregated, the mass deposition is accompanied by a very steep increase of dissipation, indicating the growing film is viscoelastic. We interpret this as differences in solvation when the film is formed from P3HT chains or larger P3HT aggregates, which are more likely to form a mesoporous scaffold, which drags the solution as the quartz crystal oscillates in the transverse direction. The fact that the assembly of the pre-aggregated polymer at the solid-liquid interface is more dissipative is consistent with film formation proceeded by self-assembly of solvated 
pre-aggregates of P3HT on the substrate surface, in contrast with the case of untreated solutions where interfacial assembly more likely proceeds via attachment of disordered polymer chains and subsequent aggregation at the solid-liquid interface through heterogeneous nucleation. In all cases, the OTS treatment enhances mass deposition with more pronounced viscoelastic behaviour, suggesting that the OTS-treated surface may have a preference for self-assembly of aggregates (both from the untreated and treated solutions) rather than solvated chains. We propose that this mechanism promotes the formation of a higher quality interface and better templates the solidification of the remaining polymer when the solution dries. The observation that $\Delta D$ vs $\Delta f$ is generally linear for untreated solutions on either substrate but distinctly non-linear when the solution is pre-aggregated suggests changes occur in mass deposition mode over time in the latter case. ${ }^{63}$ Indeed, the dissipation increases at a smaller rate for higher $\Delta f$, indicating that the solvated layer may gradually densify.

Of course, the above analysis was performed in an enclosed flow cell without the effects of solution outflow and solvent evaporation common to spin-coating. Nevertheless, we believe the experiment reveals important trends in the self-assembly behaviour, which are expected to be valid during solution-processing of thin films. The dramatically different self-assembly behaviour from pre-aggregated and pristine solutions indicates that spin-coating of pre-aggregated solutions should be first dominated by self-assembly of aggregates at the solution-solid interface. The presence of OTS treatment should also promote adhesion of the P3HT aggregates rather than solvated chains, thus promoting improved ordering at the semiconductor-dielectric interface.

\subsection{Microstructure and morphology of P3HT films}

The morphology and microstructure of spin-cast P3HT films were imaged using atomic force microscopy (AFM) and transmission electron microscopy (TEM), respectively, as shown in Figure 4a. The AFM micrographs of the top surface reveal the formation of micrometer-long fibrils in films 
cast from pre-aggregated solutions, resulting in increasing surface roughness [root mean squared (RMS)] from $2.9 \mathrm{~nm}(4.4 \mathrm{~nm})$ on $\mathrm{SiO}_{2}\left(\mathrm{SiO}_{2} / \mathrm{OTS}\right)$ to $5.9 \mathrm{~nm}(6.4 \mathrm{~nm})$. The surface morphology of the films cast on untreated and OTS-treated $\mathrm{SiO}_{2}$ is otherwise indistinguishable. The TEM micrographs looking through the film reveal more extensive fibril formation on the OTS-treated substrate. The selected area electron diffraction (SAED) analysis of the samples also reveals stronger diffraction from the (020) diffraction peak corresponding to crystalline order along the $\pi$-stacking direction in the case of the film cast on OTS-treated $\mathrm{SiO}_{2}$ (see Figure $\mathbf{S 3}$ for details). These observations support the idea that the OTS-treatment promotes the self-assembly of pre-aggregates at the solid-liquid interface, which can subsequently grow into the extended fibrils. As spin coating is known to lost most of the solution through ejection and radial outflow, ${ }^{51}$ the strong interactions between the alkyl chains and the pre-aggregates and their tendency to more rapidly attach to the OTS-treated surface may contribute to increasing the concentration of aggregates near the solution-solid interface, while solvated P3HT is present in the middle and near the top of the solution. Hence, aggregates are less likely to be lost in the outflow, leading to a preferential outflow mechanism similar to recent reports in spin-cast polymer-molecule blend OTFTs. ${ }^{64}$

We have further investigated the microstructure and texture of the films by X-ray diffraction (XRD). The (100) out-of-plane lamellar diffraction intensity integrated from XRD measurements suggests increasing lamellar crystallinity and texture with ultrasonication time, both on $\mathrm{SiO}_{2}$ and $\mathrm{SiO}_{2} / \mathrm{OTS}$ substrates (Figure 4b). The enhancement of lamellar crystallinity appears to be measurably stronger on $\mathrm{SiO}_{2} / \mathrm{OTS}$, as highlighted by increasing integrated intensity of the diffraction peak. The crystalline correlation length of $\mathrm{P} 3 \mathrm{HT}$ along the lamellar direction was calculated from the (100) peak width by the Debye-Scherrer method and is plotted in Figure 4c. ${ }^{65}$ The correlation length decreases slightly from ca. $19 \mathrm{~nm}$ to ca. $17 \mathrm{~nm}$ with solution treatment time on both surfaces, indicative of the reduced crystallite size attributed to the effect of ultrasonication, as previously shown by dynamic light scattering. ${ }^{13}$ The full width at half maximum (FWHM) of the azimuthal 
angular intensity distribution of the (100) Bragg sheet measured by GIWAXS is also plotted in Figure 4d (see Figure S4 for more details). The FWHM is a measure of mosaicity and decreases monotonically on both surfaces with solution treatment, but does not seem to be affected by the surface treatment itself. This likely indicates that self-assembled pre-aggregates are preferentially oriented at the semiconductor-dielectric interface with their lamellar stacking plane parallel to the substrate plane.

\subsection{Local order in P3HT films}

We investigate how the combination of solution pre-aggregation and surface functionalization impact the local order in P3HT films. The photophysical aggregation of the conjugated monomer units, both in terms of inter-chain and intra-chain interactions, can be analysed by UV-Vis absorption (Figure S5). The absorption spectrum is composed of a lower energy contribution from photophysical aggregates and a higher energy contribution from more disordered chains. The spectra were modelled using the Spano model according to equation (1) below, which has been successfully implemented and described in detail elsewhere (Figure 5a): ${ }^{13,43,44,66-68}$

$$
\mathrm{A}(E) \propto \sum_{m=0}\left(\frac{S^{m}}{m !}\right) \times\left(1-\frac{W e^{-s}}{2 E_{p}} \sum_{\mathrm{n} \neq \mathrm{m}} \frac{S^{n}}{n ! n-(m)}\right)^{2} \times \exp \left(\frac{\left(E-E_{0-0}-\mathrm{m} E_{p}-1 / 2 W S^{m} e^{-S}\right)^{2}}{2 \sigma^{2}}\right)
$$

Here, $A$ is the absorbance as a function of the photon energy $(E), W$ is the free exciton bandwidth of the aggregates, $S$ is the Huang-Rhys factor and fixed at 1.0 taken from a Franck-Condon fit, $m$ and $n$ are differing vibrational levels, $E_{0-0}$ is the $0-0$ transition energy, $E_{\mathrm{p}}$ is the intermolecular vibrational energy and taken as $0.18 \mathrm{eV}$, and $\sigma$ is the Gaussian line width. 

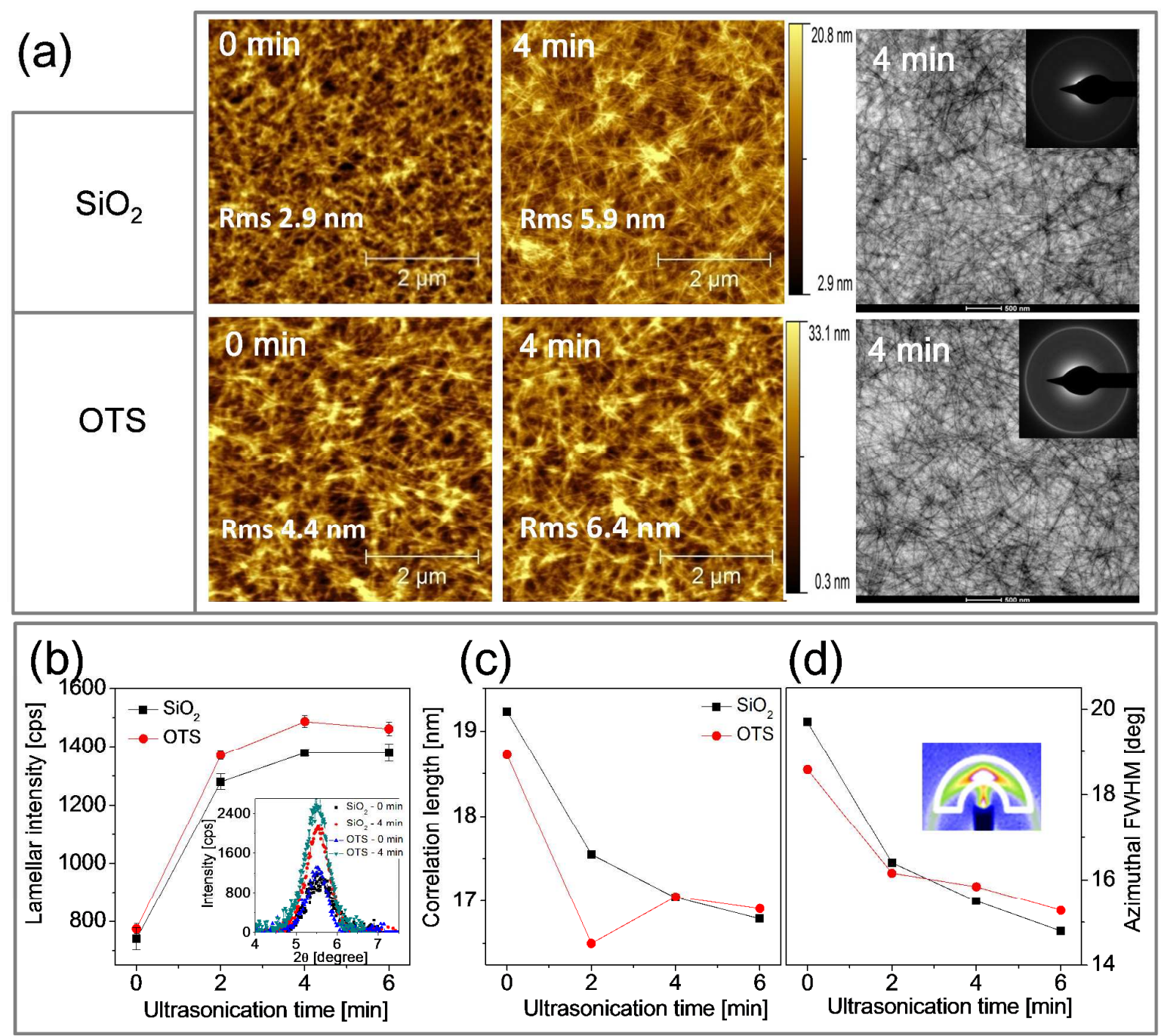

Figure 4. (a) Atomic force microscopy (AFM) and transmission electron microscopy (TEM) images showing crystalline morphologies for the entangled/disentangled films at both substrates. (b) The (100) Bragg peak intensity normalized to film thickness from XRD showing variation of lamellar stacking crystallinity for both films at OTS and $\mathrm{SiO}_{2}$ substrates. (c) Correlation length of P3HT crystallites for both films at OTS and $\mathrm{SiO}_{2}$ substrates. (d) The full width half maximum (FWHM) of the azimuthal-angle intensity of the $q_{\mathrm{z}}=(100)$ peak from GIWAXS for both films at OTS and $\mathrm{SiO}_{2}$ substrates. 
(a)
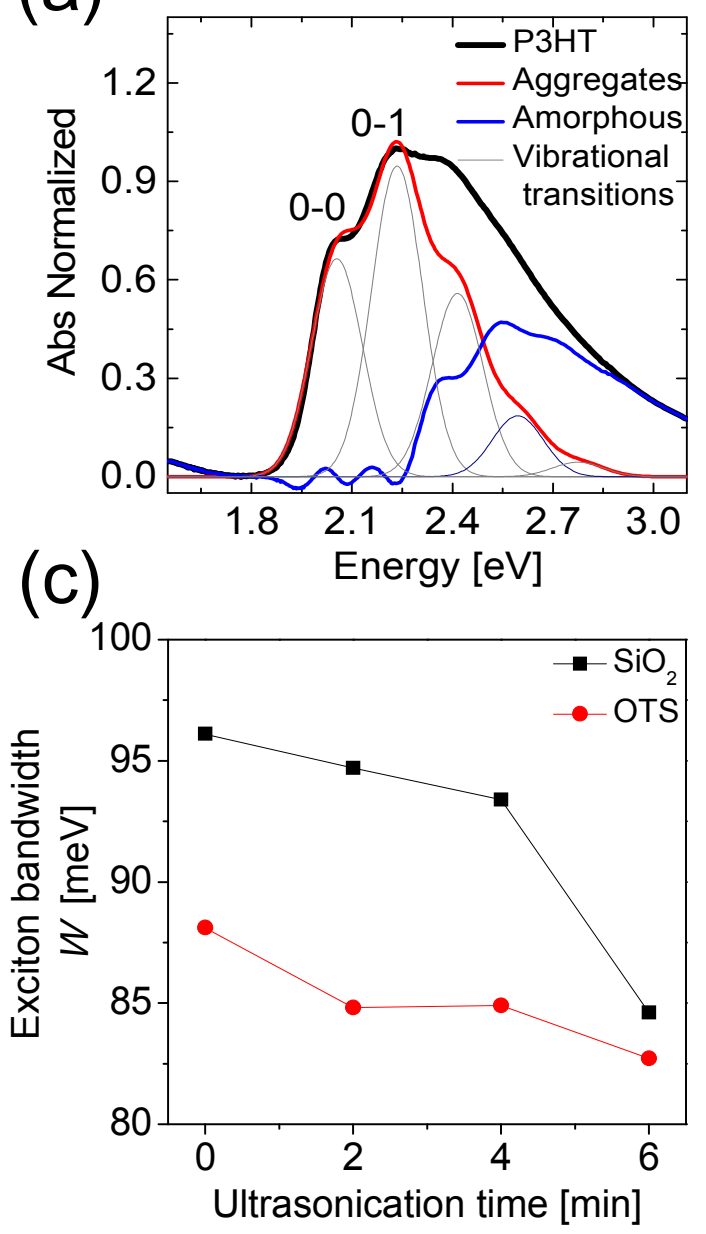

(b)

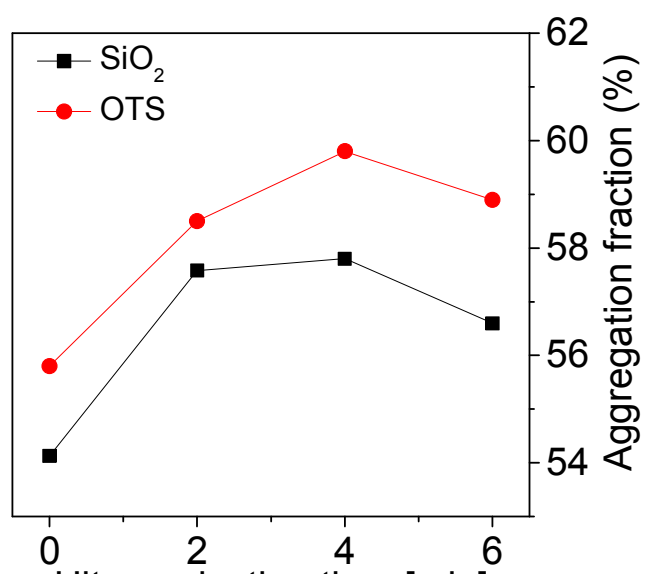

(d)

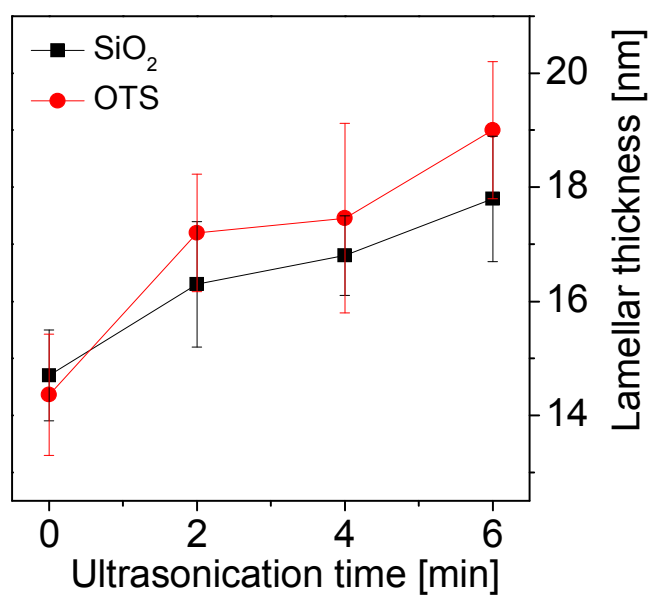

Figure 5. (a) Absorption spectrum of P3HT thin-film subjected to the Spano analysis. (b) The fraction of film made up of aggregates. (c) The evolution of exciton bandwidth $W$ of P3HT films. (d) Lamellar thickness of P3HT fibrils measured from plan-view TEM.

Based on the Spano analysis, we have calculated the total fraction of photophysical aggregates, or aggregation fraction, as well as the exciton bandwidth, $W$, which is inversely related to the exciton conjugation length (also known as intra-chain exciton coupling) along the backbone. A decreasing exciton bandwidth is therefore indicative of improving backbone planarity. ${ }^{44}$ The fraction of P3HT photophysical aggregates increases with ultrasonication time less than 6 min, but is systematically higher by ca. $1 \%$ on $\mathrm{SiO}_{2} / \mathrm{OTS}$ as compared with bare $\mathrm{SiO}_{2}$. The exciton bandwidth $W$ is found to 
decrease steadily with ultrasonication time, and is once again consistently lower on the $\mathrm{SiO}_{2} / \mathrm{OTS}$ surface. These bulk measurements of the average local order over the entire film thickness indicate that surface functionalization and solution pre-treatments can improve the local order and backbone planarity within the polymer film. The lamellar thickness of P3HT fibrils is a key microstructural feature related to backbone extension/planarity and is measurable by TEM (Figure S6). In Figure 5d we show the increasing trend of lamellar thickness with ultrasonication time. The lamellar thickness increases more notably on the $\mathrm{SiO}_{2}$ /OTS substrate than on bare $\mathrm{SiO}_{2}$, providing independent confirmation of the chain extension in the P3HT films yielding high carrier mobility. While the long range structural benefits of OTS functionalization of the substrate were found to be similar on bare and on OTS-treated surfaces, the local order and backbone planarity and extension are improved by the combination of these treatments. This observation further supports a growing body of work suggesting that local order may be more crucial to improving the operation of polymer-based OTFTs. ${ }^{13,17,66,69-72}$

As mentioned above, the structural and optical analyses are bulk measurements, whereas transport measurements in the context of OTFTs is far more sensitive to the polymer order and conformation at the interface. ${ }^{11}$ Since surface functionalization has an enhancing effect limited to within approximately $10 \mathrm{~nm}$ of the modified interface, ${ }^{11,40}$ we speculate that the measured improvements in local order averaged over the entire film depth may be even more pronounced at the interface, perhaps explaining the dramatic enhancement of carrier mobility by nearly two orders of magnitude.

\section{CONCLUSIONS}

P3HT-based OTFTs fabricated by spin-casting pristine and ultrasonicated solutions on bare and OTS-treated $\mathrm{SiO}_{2}$ gate dielectric showed very significant enhancement of carrier mobility, by up to two orders of magnitude, pointing to important changes to the P3HT local and long range order at the 
buried semiconductor-dielectric interface as well as in the bulk. The in situ QCM-D measurements revealed that P3HT solution in a theta solvent prefers to spontaneously adsorb at the solution-solid interface. When the P3HT solution was disentangled and pre-aggregated via ultrasonication, this promoted its rapid adsorption on the substrate, nearly 5 times faster than the pristine solution. The OTS surface treatment further promoted P3HT deposition at the solution-solid interface and appeared to promote the self-assembly of aggregates rather than solvated polymer chains.

The long range crystalline order (lamellar) and the local photophysical order in the P3HT films were evaluated by X-ray diffraction and optical absorption analyses, respectively. The analysis revealed enhanced lamellar crystallinity, texture and reduced mosaicity when the solution was pre-aggregated, but the structural benefits were found to be similar on bare and on OTS-treated surfaces. The local order, however, was distinctly better in terms of total fraction of photophysical aggregates as well as backbone conjugation length and planarity when the pre-aggregated solution was cast on the OTS-treated substrate.

The bulk measurements averaged the structural benefits over the entire film thickness. When taken with the dramatic improvements of carrier transport at the semiconductor-dielectric interface in OTFTs, they suggest important enhancements to interfacial ordering, which we attribute to the synergistic effects of polymer disentanglement/pre-aggregation on the one hand and enhanced interfacial adsorption and ordering on the OTS-terminated $\mathrm{SiO}_{2}$ surface.

\section{ASSOCIATED CONTENT \\ Supporting Information \\ The Supporting Information is available free of charge via the Internet at http://pubs.acs.org. \\ Figure S1 and Table S1 summarize the electrical characteristics of representative OTFTs. Figure S2 shows the Voigt model used to analyze the QCM-D data. Additional experimental results, including electron diffraction, GIWAXS, UV-Vis absorption and TEM analyses are shown in Figures S3-S6.}




\section{AUTHOR INFORMATION \\ Corresponding Author \\ *E-mail: Aram.Amassian@kaust.edu.sa.}

Notes

The authors declare no competing financial interest.

\section{ACKNOWLEDGMENT}

Part of this work was supported by the King Abdullah University of Science and Technology (KAUST). CHESS is supported by NSF \& NIH/NIGMS via NSF award DMR-1332208. AA is grateful to SABIC for the Career Development SABIC Chair.

\section{REFERENCES:}

(1)Arias, A. C.; MacKenzie, J. D.; McCulloch, I.; Rivnay, J.; Salleo, A. Materials and Applications for Large Area Electronics: Solution-Based Approaches. Chem. Rev. 2010, 110, 3-24.

(2) Friend, R. H.; Gymer, R. W.; Holmes, A. B.; Burroughes, J. H.; Marks, R. N.; Taliani, C.; Bradley, D. D. C.; Santos, D. A. D.; Bredas, J. L.; Logdlund, M.; Salaneck, W. R. Electroluminescence in Conjugated Polymers. Nature 1999, 397, 121-128.

(3) Zhou, Y.; Fuentes-Hernandez, C.; Shim, J.; Meyer, J.; Giordano, A. J.; Li, H.; Winget, P.; Papadopoulos, T.; Cheun, H.; Kim, J.; Fenoll, M.; Dindar, A.; Haske, W.; Najafabadi, E.; Khan, T. M.; Sojoudi, H.; Barlow, S.; Graham, S.; Brédas, J.-L.; Marder, S. R.; Kahn, A.; Kippelen, B. A Universal Method to Produce Low-Work Function Electrodes for Organic Electronics. Science 2012, $336,327-332$.

(4) Sirringhaus, H.; Tessler, N.; Friend, R. H. Integrated Optoelectronic Devices Based on Conjugated Polymers. Science 1998, 280, 1741-1744. 
(5) Sirringhaus, H.; Ando, M. Materials Challenges and Applications of Solution-Processed Organic Field-Effect Transistors. MRS Bull. 2008, 33, 676-682.

(6) Bao, Z.; Dodabalapur, A.; Lovinger, A. J. Soluble and Processable Regioregular Poly (3 hexylthiophene) for Thin Film Field - Effect Transistor Applications with High Mobility. Appl. Phys. Lett. 1996, 69, 4108-4110.

(7) Mcculloch, I.; Heeney, M.; Chabinyc, M. L.; Delongchamp, D.; Kline, R. J.; Coelle, M.; Duffy, W.; Fischer, D.; Gundlach, D.; Hamadani, B.; Hamilton, R.; Richter, L.; Salleo, A.; Shkunov, M.; Sporrowe, D.; Tierney, S.; Zhong, W. Semiconducting Thienothiophene copolymers: Design, Synthesis, Morphology, and Performance in Thin - Film Organic Transistors. Adv. Mater. 2009, 21, 1091-1109.

(8) Mena-osteritz, E.; Meyer, A.; Langeveld, B. M. W.; Janssen, R. A. J.; Meijer, E. W.; Bäuerle, P. Two-Dimensional Crystals of Poly (3-Alkyl-thiophene)s: Direct Visualization of Polymer Folds in Submolecular Resolution. Angew. Chem. Int. Ed. 2000, 39, 2791-2796.

(9) Hu, W. B.; Frenkel, D. "Polymer Crystallization Driven by Anisotropic Interactions" Adv. Polym. Sci. Springer-Verlag Berlin Heidelberg, 2005.

(10) Ihn, K. J.; Moulton, J.; Smith, P. Whiskers of Poly(3-alkylthiophene)s. J. Polym. Sci., Part B: Polym. Phys. 1993, 31, 735-742.

(11) Jimison, L. H.; Himmelberger, S.; Duong, D. T.; Rivnay, J.; Toney, M. F.; Salleo, A. Vertical Confinement and Interface Effects on the Microstructure and Charge Transport of P3HT Thin Films. J. Polym. Sci., Part B: Polym. Phys. 2013, 51, 611-620.

(12) Zhao, K.; Xue, L.; Liu, J.; Gao, X.; Wu, S.; Han, Y.; Geng, Y. A New Method to Improve Poly(3-hexyl thiophene)(P3HT) Crystalline Behavior: Decreasing Chains Entanglement to Promote Order- Disorder Transformation in Solution. Langmuir 2010, 26, 471-477. 
(13) Zhao, K.; Khan, H. U.; Li, R.; Su, Y.; Amassian, A. Entanglement of Conjugated Polymer Chains Influences Molecular Self - Assembly and Carrier Transport. Adv. Funct. Mater. 2013, 23, 6024-6035.

(14) Jo, S. B.; Lee, W. H.; Qiu, L.; Cho, K. Polymer Blends With Semiconducting Nanowires for Organic Electronics. J. Mater. Chem., 2012, 22, 4244-4260.

(15) Brinkmann, M.; Hartmann, L.; Kayunkid, N.; Djurado, D. Understanding the Structure and Crystallization of Regioregular Poly (3-hexylthiophene) from the Perspective of Epitaxy. Adv. Polym. Sci., 2014, 265, 83-106.

(16) Koch, F. P. V., Rivnay, J., Foster, S., Müller, C., Downing, J. M., Buchaca-Domingo, E., Westacott, P.; Yu, L.; Yuan, M.; Baklar, M.; Fei, Z.; Luscombe, C.; McLachlan, M. A.; Heeney, M.; Rumbles, G.; Silva, C.; Salleo, A.; Nelson, J.; Smith, P.; Stingelin, N. The Impact of Molecular Weight on Microstructure and Charge Transport in Semicrystalline Polymer SemiconductorsPoly(3-hexylthiophene), A Model Study. Prog. Polym. Sci., 2013, 38, 1978-1989.

(17) Hu, H.; Zhao, K.; Fernandes, N.; Boufflet, P.; Bannock, J. H.; Yu, L.; de Mello, J. C.; Stingelin, N.; Heeney, M.; Giannelise, E. P.; Amassian, A. Entanglements in Marginal Solutions: a Means of Tuning Pre-aggregation of Conjugated Polymers with Positive Implications for Charge Transport. $J$. Mater. Chem. C, 2015, 3, 7394-7404.

(18) Prosa, T. J.; Winokur, M. J.; Moulton, J.; Smith, P.; Heeger, A. J.; X-ray Structural Studies of Poly (3-alkylthiophenes): an Example of an Inverse Comb. Macromolecules 1992, 25, 4364-4372.

(19) Tsao, H. N.; Müllen, K. Improving Polymer Transistor Performance via Morphology Control. Chem. Soc. Rev. 2010, 39, 2372-2386.

(20) Brinkmann, M.; Wittmann, J.-C. Orientation of Regioregular Poly (3 - hexylthiophene) by Directional Solidification: a Simple Method to Reveal the Semicrystalline Structure of a Conjugated Polymer. Adv. Mater. 2006, 18, 860-863. 
(21) Salleo, A.; Kline, R. J.; DeLongchamp, D. M.; Chabinyc, M. L. Microstructural Characterization and Charge Transport in Thin Films of Conjugated Polymers. Adv. Mater. 2010, 22, 3812-3838.

(22) Fu, Y.; Lin, C.; Tsai, F.-Y. High Field-Effect Mobility from Poly (3-hexylthiophene) Thin-Film Transistors by Solvent-Vapor-Induced Reflow. Org. Electron. 2009, 10, 883-888.

(23) Kiriy, N.; Jahne, E.; Adler, H.-J.; Schneider, M.; Kiriy, A.; Gorodyska, G.; Minko, S.; Jehnichen, D.; Simon, P.; Fokin, A. A.; Stamm, M. One-Dimensional Aggregation of Regioregular Polyalkylthiophenes. Nano Lett. 2003, 3, 707-712.

(24) Roehling, J. D.; Arslan, I.; Moulé, A. J. Controlling Microstructure in Poly(3-hexylthiophene) Nanofibers. J. Mater. Chem., 2012, 22, 2498-2506.

(25) Kline, R. J.; McGehee, M. D.; Kadnikova, E. N.; Liu, J.; Fréchet, J. M. J.; Toney, M. F. Dependence of Regioregular Poly (3-hexylthiophene) Film Morphology and Field-Effect Mobility on Molecular Weight. Macromolecules 2005, 38, 3312-3319.

(26) Scavia, G.; Porzio, W.; Destri, S.; Barba, L.; Arrighetti, G.; Milita, S.; Fumagalli, L.; Natali, D.; Sampietro, M. Effect of the Silanization and Annealing on the Morphology of Thin Poly (3-hexylthiophene)(P3HT) Layer on Silicon Oxide. Surf. Sci. 2008, 602, 3106-3115.

(27) Rawcliffe, R.; Shkunov, M.; Heeney, M.; Tierney, S.; McCulloch, I.; Campbell, A. Organic Field-Effect Transistors of Poly (2, 5-bis (3-dodecylthiophen-2-yl) Thieno [2, 3-b] thiophene) Deposited on Five Different Silane Self-Assembled Monolayers. Chem. Commun. 2008, 7, 871-873.

(28) Roy, I.; Hazra, S. Poor Solvent and Thermal Annealing Induced Ordered Crystallites in Poly (3-dodecylthiophene) Films. RSC $A d v$. 2015, 5, 665-675.

(29) Xiao, X.; Wang, Z.; Hu, Z.; He, T. Single Crystals of Polythiophene with Different Molecular Conformations Obtained by Tetrahydrofuran Vapor Annealing and Controlling Solvent Evaporation. J. Phys. Chem. B 2010, 114, 7452-7460. 
(30) Fu, C.-M.; Jeng, K.-S.; Li, Y.-H.; Hsu, Y.-C.; Chi, M.-H.; Jian, W.-B.; Chen, J.-T. Effects of Thermal Annealing and Solvent Annealing on the Morphologies and Properties of Poly (3 hexylthiophene) Nanowires. Macromol. Chem. Phys. 2015, 216, 59-68.

(31) Aiyar, A. R.; Hong, J. I.; Nambiar, R.; Collard, D. M.; Reichmanis, E. Tunable Crystallinity in Regioregular Poly (3 - hexylthiophene) Thin Films and Its Impact on Field Effect Mobility. $A d v$. Funct. Mater. 2011, 21, 2652-2659.

(32) Zhao, K.; Yu, X.; Li, R.; Amassian, A.; Han, Y. Solvent-Dependent Self-assembly and Ordering in Slow-Drying Drop-Cast Conjugated Polymer Films. J. Mater. Chem. C, 2015, 3, 9842-9848.

(33) Ward, J. W.; Li, R.; Obaid, A.; Payne, M. M.; Smilgies, D-M.; Anthony, J. E.; Amassian, A.; Jurchescu, O. D. Rational Design of Organic Semiconductors for Texture Control and Self Patterning on Halogenated Surfaces. Adv. Funct. Mater. 2014, 24, 5052-5058.

(34) Kline, R. J.; Hudson, S. D.; Zhang, X.; Gundlach, D. J.; Moad, A. J.; Jurchescu, O. D.; Jackson, T. N.; Subramanian, S.; Anthony, J. E.; Toney, M. F.; Richter, L. J. Controlling the Microstructure of Solution-Processable Small Molecules in Thin-Film Transistors through Substrate Chemistry. Chem. Mater., 2011, 23, 1194-1203.

(35) Li, R.; Ward, J. W.; Smilgies, D. M.; Payne, M. M.; Anthony, J. E.; Jurchescu, O. D.; Amassian, A. Direct Structural Mapping of Organic Field - Effect Transistors Reveals Bottlenecks to Carrier Transport. Adv. Mater. 2012, 24, 5553-5558.

(36) Niazi, M. R.; Li, R.; Abdelsamie, M.; Zhao, K.; Anjum, D. H.; Payne, M. M.; Anthony, J.; Smilgies, D.-M.; Amassian, A. Contact - Induced Nucleation in High - Performance Bottom Contact Organic Thin Film Transistors Manufactured by Large - Area Compatible Solution Processing. Adv. Funct. Mater. 2015, 26, 2371-2378. 
(37) Chua, L. L.; Zaumseil, J.; Chang, J. F.; Ou, E. C.-W.; Ho, P. K.-H.; Sirringhaus, H.; Friend, R. H. General Observation of N-type Field-Effect Behaviour in Organic Semiconductors. Nature 2005, 434, 194-199.

(38) Martinelli, N. G.; Savini, M.; Muccioli, L.; Olivier, Y.; Castet, F.; Zannoni, C.; Beljonne, D.; Cornil, J. An Atomistic Description of Polymer Dielectrics/Pentacene Interfaces: Influence of Electrostatic Interactions on Charge Mobility Values. Adv. Funct. Mater. 2009, 19, 3254-3261.

(39) Kline, R. J.; McGehee, M. D.; Toney, M. F. Highly Oriented Crystals at the Buried Interface in Polythiophene Thin-Film Transistors. Nat. Mater. 2006, 5, 222-228.

(40) Kim, D. H.; Park, Y. D.; Jang, Y.; Yang, H.; Kim, Y. H.; Han, J. I.; Moon, D. G.; Park, S.; Chang, T.; Chang, C.; Joo, M.; Ryu, C. Y.; Cho, K. Enhancement of Field - Effect Mobility Due to Surface - Mediated Molecular Ordering in Regioregular Polythiophene Thin Film Transistors. Adv. Funct. Mater. 2005, 15, 77-82.

(41) Kim, D. H.; Jang, Y.; Park, Y. D.; Cho, K. Layered Molecular Ordering of Self-Organized Poly (3-hexylthiophene) Thin Films on Hydrophobized Surfaces. Macromolecules 2006, 39, 5843-5847.

(42) Zaumseil, J. P3HT and Other Polythiophene Field-Effect Transistors: P3HT Revisited-From Molecular Scale to Solar Cell Devices. Springer Berlin Heidelberg, 2014, pp 107-137.

(43) Spano, F. C.; Silva, C. H-and J-Aggregate Behavior in Polymeric Semiconductors. Annu. Rev. Phys. Chem. 2014, 65, 477-500.

(44) Turner, S. T.; Pingel, P.; Steyrleuthner, R.; Crossland, E. J. W.; Ludwigs, S.; Neher, D. Quantitative Analysis of Bulk Heterojunction Films Using Linear Absorption Spectroscopy and Solar Cell Performance. Adv. Funct. Mater. 2011, 21, 4640-4652.

(45) Oh, J. Y.; Shin, M.; Lee, T. I.; Jang, W. S.; Min, Y.; Myoung, J.-M.; Baik, H. K.; Jeong, U. Self-Seeded Growth of Poly (3-hexylthiophene)(P3HT) Nanofibrils by a Cycle of Cooling and Heating in Solutions. Macromolecules 2012, 45, 7504-7513. 
(46) Armistead, K.; Goldbeck-Wood, G. Polymer Crystallization Theories. Adv. Polym. Sci.,1992, $100,219-312$.

(47) Heffner, G. W.; Pearson, D. S.; Molecular Characterization of Poly (3-hexylthiophene). Macromolecules 1991, 24, 6295-6299.

(48) Schmidt-Hansberg, B.; Sanyal, M.; Klein, M. F. G.; Pfaff, M.; Schnabel, N.; Jaiser, S.; Vorobiev, A.; Müller, E.; Colsmann, A.; Scharfer, P.; Gerthsen, D.; Lemmer, U.; Barrena, E.; Schabel, W. Moving through the Phase Diagram: Morphology Formation in Solution Cast PolymerFullerene Blend Films for Organic Solar Cells. ACS Nano 2011, 5, 8579-8590.

(49) Sanyal, M.; Schmidt-Hansberg, B.; Klein, M. F. G.; Colsmann, A.; Munuera, C.; Vorobiev, A.; Lemmer, U.; Schabel, W.; Dosch, H.; Barrena, E. In situ X - ray Study of Drying - Temperature Influence on the Structural Evolution of Bulk - Heterojunction Polymer-Fullerene Solar Cells Processed by Doctor - Blading. Adv. Energy Mater. 2011, 1, 363-367.

(50) Wang, T.; Dunbar, A. D. F.; Staniec, P. A.; Pearson, A. J.; Hopkinson, P. E.; MacDonald, J. E.; Lilliu, S.; Pizzey, C.; Terrill, N. J.; Donald, A. M.; Ryan, A. J.; Jones, R. A. L.; Lidzey, D. G. The Development of Nanoscale Morphology in Polymer: Fullerene Photovoltaic Blends During Solvent Casting. Soft Matter 2010, 6, 4128-4134.

(51) Chou, K. W.; Yan, B.; Li, R.; Li, E. Q.; Zhao, K.; Anjum, D. H.; Alvarez, S.; Gassaway, R.; Biocca, A.; Thoroddsen, S. T.; Hexemer, A.; Amassian, A. Spin - Cast Bulk Heterojunction Solar Cells: a Dynamical Investigation. Adv. Mater. 2013, 25, 1923-1929.

(52) Abdelsamie, M.; Zhao, K.; Niazi, M. R.; Chou, K. W.; Amassian, A. In Situ UV-visible Absorption During Spin-Coating of Organic Semiconductors: a New Probe for Organic Electronics and Photovoltaics. J. Mater. Chem. C, 2014, 2, 3373-3381.

(53) Chou, K. W.; Khan, H. U.; Yan, B.; Li, R.; Payne, M. M.; Anthony, J. E.; Smilgies, D. M.; Amassian, A. Late Stage Crystallization and Healing During Spin-Coating Enhance Carrier Transport in Small-Molecule Organic Semiconductors. J. Mater. Chem. C, 2014, 2, 5681-5689. 
(54) McDowell, C.; Abdelsamie, M.; Zhao, K.; Smilgies, D.-M.; Bazan, G. C.; Amassian, A. Synergistic Impact of Solvent and Polymer Additives on the Film Formation of Small Molecule Blend Films for Bulk Heterojunction Solar Cells. Adv. Energy Mater. 2015, 5, 1-9.

(55) Abdelsamie, M.; Treat, N. D.; Zhao, K.; McDowell, C.; Burgers, M. A.; Li, R.; Smilgies, D.-M.; Stingelin, N.; Bazan, G. C.; Amassian, A. Toward Additive - Free Small - Molecule Organic Solar Cells: Roles of the Donor Crystallization Pathway and Dynamics. Adv. Mater. 2015, 27, $7285-7292$.

(56) Li, R.; Khan, H. U.; Payne, M. M.; Smilgies, D. M.; Anthony, J. E.; Amassian, A. Heterogeneous Nucleation Promotes Carrier Transport in Solution - Processed Organic Field Effect Transistors. Adv. Funct. Mater. 2013, 23, 291-297.

(57) Khan, H. U.; Li, R.; Ren, Y.; Chen, L.; Payne, M. M.; Bhansali, U. S.; Smilgies, D.-M.; Anthony, J. E.; Amassian, A. Solvent Vapor Annealing in the Molecular Regime Drastically Improves Carrier Transport in Small-Molecule Thin-Film Transistors. ACS Appl. Mater. Interfaces 2013, 5, 2325-2330.

(58) Kirmani, A. R.; Carey, G.; Abdelsamie, M.; Yan, B.; Cha, D.; Jagadamma, L. K.; Gereige, I.; Li, R.; Cui, X.; Sargent, E. H.; Amassian, A. Effect of Solvent Environment on Colloidal Quantum - Dot Solar - Cell Manufacturability and Performance. Adv. Mater. 2014, 26, 4717-4723.

(59) Rodahl, M.; Höök, F.; Krozer, A.; Brzezinski, P.; Kasemo, B. Quartz Crystal Microbalance Setup for Frequency and Q - Factor Measurements in Gaseous and Liquid Environments. Rev. Sci. Instrum., 1995, 66, 3924-3930.

(60) Eita, M. In Situ Study of the Adsorption of Humic Acid on the Surface of Aluminium Oxide by QCM-D Reveals Novel Features. Soft Matter 2011, 7, 709-715.

(61) Höök, F.; Kasemo, B.; Nylander, T.; Fant, C.; Sott, K.; Elwing, H. Variations in Coupled Water, Viscoelastic Properties, and Film Thickness of a Mefp-1 Protein Film During Adsorption and 
Cross-Linking: a Quartz Crystal Microbalance with Dissipation Monitoring, Ellipsometry, and Surface Plasmon Resonance Study. Anal Chem 2001, 73, 5796-5804.

(62) Mecea, V. M. Fundamentals of Mass Measurements. J. Therm. Anal. Calorim. 2006, 86, 9-16.

(63) Molino, P. J.; Hodson, O. M.; Quinn, J. F.; Wetherbee, R. Utilizing QCM-D to Characterize the Adhesive Mucilage Secreted by Two Marine Diatom Species In-situ and In Real-time. Biomacromolecules 2006, 7, 3276-3282.

(64) Zhao, K.; Wodo, O.; Ren, D.; Khan, M. H. U.; Niazi, R.; Hu, H.; Abdelsamie, M.; Li, R.; Li, E. Q.; Yu, L.; Yan, B.; Payne, M. M.; Smith, J.; Anthony, J. E.; Anthopoulos, T. D.; Thoroddsen, S. T.; Ganapathysubramanian, B.; Amassian, A. Vertical Phase Separation in Small Molecule: Polymer Blend Organic Thin Film Transistors Can Be Dynamically Controlled. Adv. Funct. Mater. 2016, 26, 1737-1746.

(65) Jenkins, R.; Snyder, R. L. “Introduction to X-ray Powder Diffractometry”, John Wiley \& Sons Inc., New York, 1996, p 89-91, ISBN 0-471-51339-3.

(66) Masri, Z.; Ruseckas, A.; Emelianova, E. V.; Wang, L.; Bansal, A. K.; Matheson, A.; Lemke, H. T.; Nielsen, M. M.; Nguyen, H.; Coulembier, O.; Dubois, P.; Beljonne, D.; Samuel, I. D. W. Molecular Weight Dependence of Exciton Diffusion in Poly (3 - hexylthiophene). Adv. Energy Mater. 2013, 3, 1445-1453.

(67) Spano, F. C. Absorption in Regio-regular Poly (3-hexyl) thiophene Thin Films: Fermi Resonances, Interband Coupling and Disorder. Chem. Phys. 2006, 325, 22-35.

(68) Clark, J.; Chang, J.-F.; Spano, F. C.; Friend, R. H.; Silva, C. Determining Exciton Bandwidth and Film Microstructure in Polythiophene Films Using Linear Absorption Spectroscopy. Appl. Phys. Lett. 2009, 94, 163306.

(69) Noriega, R.; Rivnay, J.; Vandewal, K.; Koch, F. P. V.; Stingelin, N.; Smith, P.; Toney, M. F.; Salleo, A. A General Relationship between Disorder, Aggregation and Charge Transport in Conjugated Polymers. Nat. Mater. 2013, 12, 1038-1044. 
1

2

3

4

5

6

7

8

9

10

11

12

13

14

15

16

17

18

19

20

21

22

23

24

25

26

27

28

29

30

31

32

33

34

35

36

37

38

39

40

41

42

43

44

45

46

47

48

49

50

51

52

53

54

55

56

57

58

59

60
(70) Choi, D.; Chang, M.; Reichmanis, E. Controlled Assembly of Poly (3 - hexylthiophene): Managing the Disorder to Order Transition on the Nano - through Meso - Scales. Adv. Funct. Mater. 2015, 25, 920-927.

(71) Kleinhenz, N.; Persson, N.; Xue, Z.; Chu, P. H.; Wang, G.; Yuan, Z.; McBride, M. A.; Chio, D.; Grover, M. A.; Reichmanis, E. Ordering of Poly (3-hexylthiophene) in Solutions and Films: Effects of Fiber Length and Grain Boundaries on Anisotropy and Mobility. Chem. Mater. 2016. 28, 3905-3913.

(72) Tremel, K.; Ludwigs, S. Morphology of P3HT in Thin Films in Relation to Optical and Electrical Properties. Springer Berlin Heidelberg, 2014; p107-137. ISBN 9783662451441. 
TOC
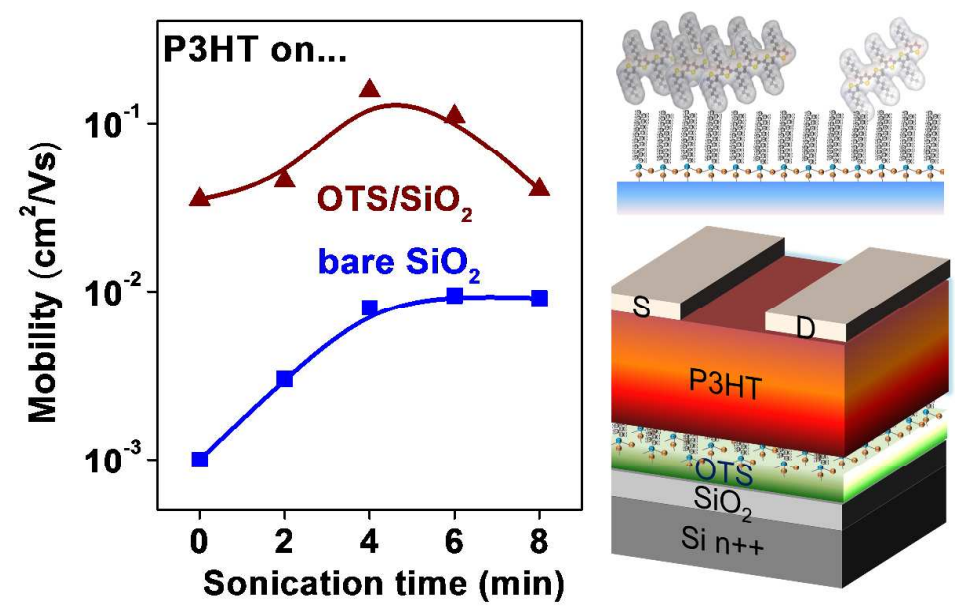

We demonstrate that deposition of conjugated polymer aggregates can be vastly improved on surfaces modified with an alkyl-terminated self-assembled monolayer (SAM) in comparison to solvated polymer chain deposition on untreated surfaces. This leads to improved local order as well as planarization and extension of the conjugated backbone which significantly improves carrier transport in organic field effect transistors. 
We demonstrate that deposition of conjugated polymer aggregates can be vastly improved on surfaces modified with an alkyl-terminated self-assembled monolayer (SAM) in comparison to solvated polymer chain deposition on untreated surfaces. This leads to improved local order as well as planarization and extension of the conjugated backbone which significantly improves carrier transport in organic field effect transistors.

\section{$130 \times 82 \mathrm{~mm}(150 \times 150 \mathrm{DPI})$}

